\title{
The Impact of Online Additional Comments on Consumers' Information Adoption
}

\author{
Hong Zhou, Sujuan Li \\ School of Management, Jinan University, Guangzhou, China \\ Email:1_sujuan@126.com
}

How to cite this paper: Zhou, H., \& Li, S. J. (2017). The Impact of Online Additional Comments on Consumers' Information Adoption. Sociology Mind, 7, 60-71. https://doi.org/10.4236/sm.2017.72005

Received: March 17, 2017

Accepted: April 24, 2017

Published: April 27, 2017

Copyright $\odot 2017$ by authors and Scientific Research Publishing Inc. This work is licensed under the Creative Commons Attribution International License (CC BY 4.0).

http://creativecommons.org/licenses/by/4.0/

\begin{abstract}
Online additional reviews, as an effective complement to network commentary system, provide an important reference during the process of consumers' purchase and businesses' operation decision-making. In this paper, we explored the impact of additional comments on consumers' information adoption in different comment combinations. At the same time, we also analyzed the moderating role of consumers' ambivalent attitude. The results show that, when initial comment is positive, compared with the consistent comments (positive initial comments and positive additional comments), consumers have a higher degree of adoption of inconsistent comments (positive initial comments and negative additional comments). On the contrary, when initial comment is negative, consistent comments (negative initial comments and negative additional comments) are more easily adopted by the consumer. Compared with the low ambivalent attitude consumers, customers with high ambivalent attitude tend to adopt negative comments.
\end{abstract}

\section{Keywords}

Additional Comment, Ambivalent Attitude, Information Adoption

\section{Introduction}

With the rapid development of e-commerce, China's online shopping market is also growing at a high speed. Among the factors that affect consumers' purchase decisions, products' e-WOM has become the most important factor for consumers. Online additional comment, as an effective complement to the network commentary system, has become the most important reference for consumers to obtain informatics on goods or services (Chevalier \& Mayzlin, 2006). Because of this, some businesses use improper means to induce consumers to make positive comments, which also has false information, and this leads online reviews to losing its meaning and value. In order to improve this situation, Taobao intro- 
duced additional evaluation function in 2012. Online additional comments can be more realistic response to the situation after the purchase, and potential consumers can also get more real and reliable information. So, more and more consumers will read additional comment information before making a purchase decision, and use it as an important basis for measuring product quality and service experience.

Additional reviews are made by consumers who used the product for a period of time, and it may be consistent with the initial comment, and of course, may be contradictory. The process of reading comments, in fact, is the process of information selection. Consumers are selective in adopting the content or views of the comments, and using them as a basis for their own purchasing decisions. After reading the information about goods or services, consumer will form ambivalent attitude (Pan \& Cheng, 2014), which will also affect their way of dealing with commentary information (Huang, Xie, \& Feng, 2010).

Based on the latest phenomenon, we explored the impact of additional comments on consumers' information adoption in different comment combinations. At the same time, we also analyzed the moderating role of consumers' ambivalent attitude. This has not been analyzed in previous studies. Using the results of our study, businesses can not only reduce the cost of word of mouth maintenance, but also can be targeted to improve the positive impact of positive comments, and bring more benefits to businesses as a result.

\section{Literature Review}

\subsection{The Impact of Additional Comments on Consumer}

Online commentary plays an important role in consumer decision-making, and many scholars have made a lot of meaningful academic research. But most of the research on online reviews mostly suggests these comments come from different consumers, but the emergence of additional comments allows customers to make multiple comments at different times. So far, the impact of additional comments on consumer has not been widely concerned by the academic community, the relevant research results are also numbered.

Chinese scholars' study about additional comments mostly focused on the impact of additional comment on consumer purchase intention, and the impact on information usefulness perception. Liu found that, compared with initial comment, additional comment not only have greater value, but also have more obvious impact on consumer purchase decision (Liu \& Xu, 2015). In comparing the difference between initial comment and additional comment, He Jingjing found that the same information placed on the additional comment position has a greater impact on consumer's willingness to buy, whether the evaluation was positive or negative (He, 2014). In discussing the usefulness of additional comment, Wang Changzheng found that, compared with a one-time review, additional comments were able to produce a higher sense of usefulness (Wang, He, \& Wang, 2015). 


\subsection{Ambivalent Attitude}

Consumer's ambivalent attitude refers to the positive (negative) and negative (negative) attitudes or emotions that people present at the same time on target goods or services (LAU-GESK, 2005), often due to the interaction of consumer's intrinsic psychological factors and external multi-factor, will directly or indirectly affect the attitude and behavior of consumer (Otens, Lowrey, \& Shrum, 1997). The study of ambivalent attitude of consumers and the study of ambivalent attitude in the field of social informatics are different. The study of consumer attitude is concerned with the ambivalent attitude that can be changed in consumption decision-making situation, which is a kind of micro-level (Huang, Xie, \& Feng, 2010).

In the study of the mechanism of ambivalent attitude, scholars have made a lot of research on the individual with different degree of contradiction, who is more likely to be influenced by the outside world. The mainstream view is that the positive and negative cognitive proximity of high contradiction, their attitudinal structure is unstable at this time, and it is easier to be persuaded to change in hesitation; there are also studies found that low contradictions are vulnerable to change attitude. Feng Xiaoliang analyzes three dimensions of attitude composition (emotion, cognition and intention), through experimental studies he found that high-contradictory consumer's emotion is easy to be changed, and cognitive attitude and intention are relatively stable, low contradictory consumers' attitude change trend is just the opposite (Feng, Huang, \& Zhang, 2013).

In study about the influence of ambivalent attitude on consumers' behavior intention, Le Chi Cong et al. found that there was a negative correlation between ambivalent attitude, consumer attitude and food choices (Le, Svein, \& Ho, 2013). Bee pointed out that the ambivalent attitude increased individual's discomfort, making the attitude very unstable, thereby increasing the possibility of delayed purchase of consumers (Bee \& Madrigal, 2013). Russell et al. found that when people hold a positive and negative view of a country at the same time, the ambivalence will have a negative impact on consumer's willingness to buy the country's brand (Russell \& Klein, 2011).

\subsection{Information Adoption}

Information adoption is derived from the theory of technology adoption, which refers to the process of objectively selecting, evaluating, accepting and utilizing information, and that the process will ultimately affect the follow-up behavior of the subject (Song \& Wang, 2010). Based on the theory of technical acceptance model (TAM) and processing possibility theory (ELM), Sussman deduced the information adoption model. The information adoption model (IAM) points out information quality and credibility of the information source jointly affect recipient's perceived usefulness of information, and the perceived usefulness of the information further influences information adoption (Sussman \& Siegal, 2003). Since then, the adoption of information is widely used in the study of e-WOM.

The research on information adoption is based on the information adoption 
model. On the basis of information adoption theory, Yin Guopeng explores the factors that affect consumers' adoption of online commentary information in purchasing decision, results show that the length of comment is positively related to the usefulness of online comment, and star rating is negatively correlated with the usefulness of online comment (Yin, Liu, \& Zhu, 2012). Li Jing found that information obtained from advertising and online reviews have a significant positive impact on information quality perception, information quality perception significantly affects the behavior of consumer information adoption (Li, Xi, \& Chen, 2015). Cheung and Luo explored the impact of online comment on the adoption of consumer information from the perspective of commentary texts and the review of consistency scores (Cheung, Luo, Sia, \& Chen, 2009). Lee and Koo test the influence of comment on the adoption of information. The results show that the objective comment has a positive effect on the reliability of information. Negative comments have a negative impact on the reliability of information, and thus affect consumer's adoption of information (Lee \& Koo, 2012).

\section{Research Hypotheses}

Considering the positive and negative of online comments, additional comment and initial comment may be consistent, but it may be the opposite or even contradictory. Previous studies suggest that when people try to persuade others or want to get support from others, constantly communicating consistent information can improve the likelihood of success (Reich \& Tormala, 2013). Sun M. studies the impact of product ratings also found that, inconsistency between word of mouth can reduce the impact on purchasing decisions (Sun, 2012). But Taly found that, when study the persuasion of contradictory information in a special context from the perspective of attribution theory, inconsistent information can enhance its persuasion effect. The impact of additional comment on consumer will also be influenced by initial comment, whether is positive or negative.

When initial comment is positive, the positive additional comment is defined as a consistent message, whereas negative comment is inconsistent information. According to self-promotion motivation, people will strengthen their own views to maintain and enhance their image (Berger \& Schwarta, 2011). So, when passing information, people are more willing to emphasize information who can suggest their good image, as far as possible to avoid those may damage their image (Richins, 1984). People maintain a self-consistent approach is to meet the needs of reducing cognitive disorders, in order to maintain their own ability and moral aspects of self-image, to avoid inconsistent threats (Maertz, Hassan, \& Magnusson, 2009).

Existing studies show that, compared with the consistent comments, inconsistent additional comment reflects the contradictory cognition of the product, reversal of attitude and emotion. This makes potential consumers think the information is abnormal, and this abnormal attitude reversal will lead information readers to infer that the attitude change of the commentator is due to external causes (Crowley \& Hoyer, 1994), readers are more likely to think that commen- 
tators are based on their own real experience to give the evaluation. Therefore, negative additional comments that contrary to the initial comments are more likely to be perceived by the consumer as a real or objective response to the product or service, preferring to use the comment as a basis for their own shopping decisions. In summary, we propose a hypothesis:

H1: When initial comment is positive, compared with consistent comment, inconsistent additional comment has a greater impact on information adoption.

When initial comment is negative, the negative additional comment is defined as a consistent message, whereas positive comment is inconsistent information. Through in-depth interviews with consumers with online shopping experience, we found that consumers often attribute this comment to external reasons when they see the combination of positive initial comment and negative additional comment, such as business incentives to give profits, business threats and so on. Consumers are relatively rational, and they have the ability to anticipate the improper conduct of the business. Then the impact of positive information on consumer decision-making will be reduced (Dellarocas, 2006), consumers' adoption of the comments also reduced (Zhao et al., 2013). Although we cannot deny that some of the comment information is true, but consumers' attribution bias also affect the subsequent decision-making behavior. Using the prospect theory, people's tendency to avoid the risk will affect their information retrieval behavior and decision-making results (Mitchell, 1999). So, negative initial comment and positive additional comment are not likely to be adopted by potential consumers. On the contrary, two negative comments will make consumers feel that this is a true reflection of the quality of the product or service, and then use it as a basis for purchase decision.

$\mathrm{H} 2$ : When initial comment is negative, compared with inconsistent comment, consistent additional comment has a greater impact on information adoption.

The ambivalent attitude is ubiquitous in daily consumption scenarios, and is particularly prominent in online consumption. On one hand, the convenience of online shopping, low cost and diversity bring immediate benefits to consumer; on the other hand, the virtuality of the network makes it impossible for customer to feel the quality of goods like offline shopping, while the time cost and uncertainty in the transportation process also increase the risk perception, this makes the consumer hesitate to buy, and then into a "tangled" state.

In online shopping situation, after reading the product or service information provided by the business, consumer will form a preliminary ambivalent attitude (Pan \& Cheng, 2014). Among them, the positive attitude reflects the consumer's expectations of future earnings, and negative attitudes reflect consumer concerns about future losses (Bee \& Madrigal, 2013). At the same time, it is influenced by factors such as preference, shopping experience and personal expectation, and different consumers have different degrees of initial attitude. In this paper, the low ambivalence attitude means that the attitude contains a lower negative attitude and a higher positive attitude, the high ambivalence attitude refers to the attitude contains a higher negative attitude and a higher positive attitude (Pan \& 
Huang, 2015).

Priester pointed out in the expected contradictory theory that, when negative attitude of the individual is weak and the positive attitude is strong, positive factors have a greater impact on consumer attitude; when negative attitude of individuals increases more than a certain value, the contradiction of individual attitudes increases, which is more affected by negative factors, and the influence of positive factors is reduced (Priester \& Petty, 1996). Pan found that positive word of mouth information has greater impact for low contradictory consumer.

H3: Ambivalent attitude has a moderating effect on consumer's information adoption. High-ambivalent attitude consumers are more likely to adopt negative additional comments, whereas low-ambivalent attitude consumers are more likely to adopt positive additional comments.

\section{Pre-Test}

In online shopping context, consumers will form an initial attitude after browsing the target goods or service information, and this initial attitude is often contradictory. In this paper, we use the manipulation method to group initial ambivalent attitude of consumers, participants were randomly assigned to different groups, and then form a high ambivalent attitude or low ambivalent attitude. By talking to consumers with online shopping experience, we selected some factors that affect consumer purchasing decision, including product sales, the cumulative number of evaluation, whether to provide freight insurance, the number of the collection of goods and so on.

Pre-experiment is to test the control effect of ambivalent attitude, the main participants are college students. Respondents were asked to read the relevant profiles first, and then fill out the questionnaire with a contradictory attitude. In this paper, consumers' ambivalent attitude scale is used by Pan Xiaobo's research, including positive attitude and negative attitude. 88 valid questionnaires were collected, among them, 46 were high ambivalent attitude and 42 were low. The experimental results show that the mean value of the overall sample is 4.3153 , there was a significant difference in the mean values of contradiction between the two groups, control effect is ideal $\left(\mathrm{M}_{\mathrm{H}}=5.0652, \mathrm{M}_{\mathrm{L}}=3.4940, p<\right.$ $0.000)$.

\section{Study One}

This study examines the additional comments from different combinations of initial and additional comments to examine the difference in the impact of additional comments on the adoption of information.

\subsection{Experimental Design}

The experiment was designed by 2 (initial comment: positive vs. negative) $\times 2$ (additional comment: positive vs. negative) groups, the experiment was conducted in 136 students in a comprehensive university, and the subjects were 
randomly assigned to 4 experimental groups. For each experimental group, we selected real online comments from Taobao. In order to reduce the influence of factors such as brand, comment time and time distance, these factors are fuzzified in the experiment, and only show relevant comments. We choose suitcase as the target product. On one hand, the use of suitcase in college students is common, student groups are more familiar with this product; on the other hand, through practical comparison, in the same kind of goods, suitcase has a higher rate of additional comments, so it is more suitable in this experimental situation.

After the start of the experiment, subjects were asked to read information about the goods, then read comments from previous consumers, and finally fill in the information adoption scale. In this study, the information adoption scale is based on a comprehensive study of Man and Hsin related research, the questionnaire uses Likert seven-point scale.

\subsection{Experimental Results and Hypothesis Tests}

A total of 131 valid questionnaires were collected, including 72 female subjects, 59 male subjects. The Cronbach' $\alpha$ coefficient was used to evaluate the internal consistency reliability of the questionnaire. The results show that the overall Cronbach' $\alpha$ coefficient of the information adoption is 0.914 , indicating that the questionnaire has a better internal consistency.

When initial comment is positive, compared with consistent comments (positive initial comment, positive additional comment), inconsistent additional comment information is more easily adopted by consumers $\left(\mathrm{M}_{\text {consistent }}=4.3879\right.$, $\mathrm{M}_{\text {inconsistent }}=5.9697, p<0.000$ ), hypothesis 1 is supported. When initial comment is negative, compared with inconsistent comments (negative initial comment, positive additional comment), consistent additional comment information is more easily adopted by consumers $\left(\mathrm{M}_{\text {consistent }}=5.4294, \mathrm{M}_{\text {inconsistent }}=4.2645, p<\right.$ $0.000)$, hypothesis 2 is supported.

\section{Study Two}

Experiment 2 introduces ambivalent attitude of consumer, examines the differences in the impact of different levels of ambivalent attitude on consumer information adoption, and simultaneously examines the main effect.

\subsection{Experimental Design}

This experiment was designed by 2 (initial comment: positive vs. negative) $\times 2$ (additional comment: positive vs. negative) $\times 2$ (ambivalent attitude: high vs. low) groups. We invited 270 college students to participate in this experiment, and they were random, evenly distributed to the above mentioned eight groups. We still choose the suitcase as the target product, and all the comments are also from Taobao real comments.

Participants were asked to read information about the goods, and then answer some questions about ambivalent attitude. The second step is to read evaluation 
of the goods from other consumers, and finally fill in the information adoption scale.

\subsection{Experimental Results and Hypothesis Tests}

A total of 265 valid questionnaires were collected, including 138 female subjects, 127 male subjects. The Cronbach' $\alpha$ coefficient was used to evaluate the internal consistency reliability of the questionnaire. The results show that the Cronbach' $\alpha$ coefficient of positive attitude is 0.947 , the Cronbach' $\alpha$ coefficient of negative attitude is 0.903 , the overall Cronbach' $\alpha$ coefficient of the information adoption is 0.904 , indicating that the questionnaire has a better internal consistency.

First, we analyze the significance of the main effect. When initial comment is positive, compared with consistent comments (positive initial comment, positive additional comment), inconsistent additional comment information is more easily adopted by consumers $\left(\mathrm{M}_{\text {consistent }}=4.7313, \mathrm{M}_{\text {inconsistent }}=5.8523, p<0.000\right)$, hypothesis 1 is supported. When initial comment is negative, compared with inconsisent comments (negative initial comment, positive additional comment), consistent additional comment information is more easily adopted by consumers $\left(\mathrm{M}_{\text {consistent }}=5.7493, \mathrm{M}_{\text {inconsistent }}=4.5294, p<0.000\right)$, hypothesis 2 is supported.

Secondly, we analyze the impact of contradictory attitude. The results show that, when additional comment is positive, the average information adoption of low-ambivalent attitude group is significantly higher than high-ambivalent attitude group; when additional comment is negative, the result is opposite; and the interaction between ambivalent attitude and additional comment is significant, $p<0.002$, hypothesis 3 is supported.

\section{Study Three}

Experiment 3 changes the target product and experimental participants, and the purpose is to expand the external validity of the experimental results.

\subsection{Experimental Design}

This experiment was designed by 2 (initial comment: positive vs. negative) $\times 2$ (additional comment: positive vs. negative) $\times 2$ (ambivalent attitude: high vs. low) groups. Participants in this experiment not only include students, but also include social workers. Similarly, participants were random, evenly distributed to the above mentioned eight groups. We choose clothing as the target product. The specific experimental process is the same as the previous two experiments.

\subsection{Experimental Results and Hypothesis Tests}

A total of 254 valid questionnaires were collected, including 122 female subjects, 132 male subjects. The Cronbach' $\alpha$ coefficient was used to evaluate the internal consistency reliability of the questionnaire. The results show that the Cronbach' $\alpha$ coefficient of positive attitude is 0.823 , the Cronbach' $\alpha$ coefficient of negative attitude is 0.822 , the overall Cronbach' $a$ coefficient of the information adoption is 0.891 , indicating that the questionnaire has a better internal consistency. 
Main effect analysis. When initial comment is positive, compared with consistent comments (positive initial comment, positive additional comment), inconsistent additional comment information is more easily adopted by consumers $\left(\mathrm{M}_{\text {consistent }}=4.4028, \mathrm{M}_{\text {inconsistent }}=5.8545, p<0.000\right)$, hypothesis 1 is supported. When initial comment is negative, compared with inconsistent comments (negative initial comment, positive additional comment), consistent additional comment information is more easily adopted by consumers $\left(\mathrm{M}_{\text {consistent }}=5.5771\right.$, $\mathrm{M}_{\text {inconsistent }}=3.9509, p<0.000$ ), hypothesis 2 is supported.

The impact of contradictory attitude. The results show that, when additional comment is positive, the average information adoption of low-ambivalent attitude group is significantly higher than high-ambivalent attitude group; when additional comment is negative, the result is opposite; and the interaction between ambivalent attitude and additional comment is significant, $p<0.000$, hypothesis 3 is supported.

\subsection{Discussion}

Compared with the existing research on additional comments, our study further analyzes the impact of different review combinations, rather than just a simple comparison between the additional comments and the initial comments. In addition, previous studies have focused on the consumer's perception of additional comments, this study extends the results of the review to the adoption of information, can be more intuitive to see the impact of comments on customers. The analysis of consumers' ambivalent attitude can provide more advice to online merchants, and thus improve the sales of goods.

\section{Conclusion and Implications}

\subsection{Research Conclusions and Management Implications}

Conclusion 1: In different combinations of comments, the effect of additional comment on the adoption of information is different.

In online shopping situation, the process by which potential consumers read online reviews is the process of selecting information, and it gives the answer to the question of what kind of comment information is chosen as the basis for the purchase of their own decisions. Studies show that, when initial comment is positive, the contradictory additional comment has a greater impact on the adoption of information; and when initial comment is negative, the consistent additional comment has a greater impact on the consumer. In one word, influenced by initial comment, additional comments have different effects on consumers in different comment combinations.

For online businesses, the maintenance of online comments and the resolution of consumers' complaints is an important factor affecting store sales. Especially with additional comments, consumers pay more attention to what kind of commentary information becomes more complicated. Using the results of this study, there are two combinations of comments (positive initial comment and negative additional comment, negative initial comment and negative additional 
comment) that have a greater impact on consumers, so businesses can put more energy on the maintenance of these two comments, thereby improving customer satisfaction, weakening the negative impact of negative comments on potential consumers. It is worth emphasizing that in the four different combinations of comments, the combination of positive initial comments and negative additional comments has the weakest impact on consumers, so businesses do not have to spend a lot of manpower and resources to guide consumers to modify comments when they see such information.

Conclusion 2: Different levels of ambivalent attitude will affect consumer's choice of comments.

After reading the information provided by the business, consumers will form a preliminary ambivalent attitude, and this attitude will affect consumer's choice of comments. For consumers with high ambivalent attitude, they pay more attention to negative additional comments; on the contrary, low ambivalence is more inclined to use positive additional comments as a basis for their purchasing decisions.

There are many factors that affect ambivalent attitude of consumers, and businesses can improve these factors to reduce consumers' ambivalent attitude, such as improving picture clarity, multi-dimensional display product information, increasing buyers show and so on, and through these means to reduce the ambivalent attitude of consumers, thereby increasing the positive impact of positive comments and reducing the negative impact of negative comments.

\subsection{Limitations and Future Research Directions}

This study also has some limitations, and the specific performance is as follows:

First, in order to avoid the impact of some other factors, we selected comments that are pure positive comments or pure negative comments. But in real life, one comment may contain positive attitude and negative attitude, which is not mentioned in this study; second, the actual comment information may be the same attribute of the product or service, and of course, may also be different attributes, and this study did not discuss; thirdly, there are many factors that affect ambivalent attitude of consumers. However, considering the length of materials in the experiment, the concentration of participants' attention and the authenticity of the data, we only discuss some factors that affect the initial ambivalent attitude of consumers.

Future research can further explore the impact of additional comments from these aspects, and further improve the theoretical system of online commentary.

\section{Acknowledgements}

This study was supported by the Social Science Foundation of Guangdong Province, China (GD12CGL15), and the Humanity and Social Science Foundation of Ministry of Education of China (14YJA630099).

\section{References}

Bee, C. C., \& Madrigal, R. (2013). Consumer Uncertainty: The Influence of Anticipatory 
Emotions on Ambivalence, Attitudes, and Intentions. Journal of Consumer Behavior, 12, 370-381. https://doi.org/10.1002/cb.1435

Berger, J., \& Schwarta, E. M. (2011). What Drives Immediate and Ongoing Word of Mouth? Journal of Marketing Research, 48, 869-880.

https://doi.org/10.1509/jmkr.48.5.869

Chevalier, J. A., \& Mayzlin, D. (2006). The Effect of Word of Mouth on Sales: Online Book Reviews. Journal of Marketing Research, 43, 345-354.

https://doi.org/10.1509/jmkr.43.3.345

Russell, C. A., Russell, D. W., \& Klein, J. (2011). Ambivalence toward a Country and Consumers' Willingness to Buy Emblematic Brands: The Differential Predictive Validity of Objective and Subjective Ambivalence Measures on Behavior. Marketing Letters, 22, 357-371. https://doi.org/10.1007/s11002-010-9129-7

Crowley, A. E., \& Hoyer, W. D. (1994). An Integrative Framework for Understanding Two-Side Persuasion. Journal of Consumer Research, 20, 561-574. https://doi.org/10.1086/209370

Dellarocas, C. (2006). Strategic Manipulation of Internet Opinion Forums: Implications for Consumers and Firms. Management Science, 52, 153-169.

https://doi.org/10.1086/209370

Feng, X., Huang, M., \& Zhang, Y. (2013). Is Ambivalent Consumer's Attitude More Easily to Be Influenced? The Differences of Attitudinal Components Changes among Ambivalent Consumers. Nankai Business Review, No. 1, 92-101.

He, J. (2014). The Impact of Additional Comments on Consumer Purchase Intention. Business Study, No. 9, 92-94.

Huang, M., Xie, T., \& Feng, X. (2010). How Do Ambivalent Consumers Interpret Diversified Word-of-Mouth Information? Acta Psychologica Sinica, 42, 998-1010. https://doi.org/10.3724/SP.J.1041.2010.00998

Lee, K.-T., \& Koo, D.-M. (2012). Effects of Attribute and Valence of E-WOM on Message Adoption: Moderating Role of Subjective Knowledge and Regulatory Focus. Computers in Human Behavior, 28, 1974-1984.

Lau-Gesk, L. (2005). Understanding Consumer Evaluations of Mixed Affective Experiences. Journal of Consumer Research, 32, 23-28. https://doi.org/10.1086/429598

Le, C. C., Olsen, S. O., \& Tuu, H. H. (2013). The Roles of Ambivalence, Preference Conflict and Family Identity: A Study of Food Choice among Vietnamese Consumers. Food Quality and Preference, 28, 92-100.

Li, J., Qi, X., \& Chen, M. (2015). Understanding the Impact of Perceived Information Quality on Information Acquisition and Information Adoption. Information Science, 3, 123-129.

Liu, X., \& Xu, L. (2015). A Study on the Influence of Online Additional Comments on Consumers' Willingness to Purchase Online. Manager Journal, No. 7, 278-279.

Maertz, C. P., Hassan, A., \& Magnusson, P. (2009). When Learning Is Not Enough: A Process Model of Expatriate Adjustment as Cultural Cognitive Dissonance Reduction. Organizational Behavior and Human Decision Processes, 108, 66-78.

Cheung, M. Y., Luo, C., Sia, C. L., \& Chen, H. (2009). Credibility of Electronic World-of-Mouth: Informational and Normative Determinants of On-Line Consumer Recommendations. International Journal of Electronic Commerce, 4, 9-38. https://doi.org/10.2753/JEC1086-4415130402

Mitchell, V. W. (1999). Consumer Perceived Risk: Conceptualisations and Models. European Journal of Marketing, 33, 163-195. https://doi.org/10.2753/JEC1086-4415130402 
Otens, C., Lowrey, T. M., \& Shrum, L. J. (1997). Toward an Understanding of Consumer Ambivalence. Journal of Consumer Research, 42, 80-93. https://doi.org/10.1086/209495

Pan, X., \& Cheng, H. (2014). How to Deal with the Positive Information of Online Shopping Leads to the Contradiction of Consumers' Attitude. Commercial Research, No. 11, 112-121.

Pan, X., \& Huang, W. (2015). How Customers' Ambivalence Affects Their Processing of Positive Online Word-of-Mouth. Chinese Journal of Management, 12, 446-457.

Priester, J. R., \& Petty, R. E. (1996). The Gradual Threshold Model of Ambivalence: Relating the Positive and Negative Bases of Attitudes to Subjective Ambivalence. Journal of Personality and Social Psychology, 71, 431-449.

https://doi.org/10.1037/0022-3514.71.3.431

Reich, T., \& Tormala, Z. L. (2013). When Contradictions Foster Persuasion: An Attributional Perspective. Journal of Experimental Social Psychology, 49, 426-439.

Sun, M. (2012). How Does the Variance of Product Ratings Matter? Management Science, 58, 696-707. https://doi.org/10.1287/mnsc.1110.1458

Richins, M. L. (1984). Word of Mouth Communication as Negative Information. Advances in Consumer Research, 11, 679-702.

Song, X., \& Wang, P. (2010). Research on Concept and Effective Factors of Information Adoption Behavior. Information Science, 28, 760-762.

Sussman, S. W., \& Siegal, W. S. (2003). Information Influence in Organizations: An Integrated Approach to Knowledge Adoption. Information Systems Research, 14, 47-56. https://doi.org/10.1287/isre.14.1.47.14767

Yin, G., Liu, W., \& Zhu, S. (2012). What Makes a Helpful Online Review?-The Perspective of Information Adoption and Social Network. Library and Information Service, 16, 140-147.

Wang, C., Shan, H., \& Wang, K. (2015). Research on How Additional Review Affects Perceived Usefulness of Review. Journal of Management Science, 28, 102-114.

Zhao, Y. S., Narayan, Y. V., \& Zhao, Y. (2013). Modeling Consumer Learning from Online Product Reviews. Marketing Science, 32, 153-169.

https://doi.org/10.1287/mksc.1120.0755

Scientific Research Publishing

Submit or recommend next manuscript to SCIRP and we will provide best service for you:

Accepting pre-submission inquiries through Email, Facebook, LinkedIn, Twitter, etc.

A wide selection of journals (inclusive of 9 subjects, more than 200 journals)

Providing 24-hour high-quality service

User-friendly online submission system

Fair and swift peer-review system

Efficient typesetting and proofreading procedure

Display of the result of downloads and visits, as well as the number of cited articles

Maximum dissemination of your research work

Submit your manuscript at: http://papersubmission.scirp.org/

Or contact sm@scirp.org 